\title{
Red blood cell concentrate transfusion strategies utilised at a tertiary-level paediatric intensive care unit: A descriptive study on impact and cost
}

\author{
P B S Radebe, MBChB, DCH, FC Paed (SA); P M Jeena, MBChB, FC Paed (SA), Cert Paed Pulmonology, PhD \\ Department of Paediatrics and Child Health, Nelson R Mandela School of Medicine, University of KwaZulu-Natal, Durban, South Africa
}

Corresponding author: P B S Radebe (palessa.radebe@gmail.com)

\begin{abstract}
Background. Optimal haemoglobin threshold for red blood cell (RBC) transfusions in critically ill anaemic children in a paediatric intensive care unit (PICU) is uncertain.

Objective. To describe outcomes and costs associated with different RBC transfusion strategies in anaemic patients admitted to a tertiary PICU in Durban, South Africa.

Methods. Transfusion data gathered over a 1-year period were analysed retrospectively. RBC transfusion strategies were classified as restrictive, 'modified liberal' or mixed. The 'modified liberal' group was subdivided into haemodynamically stable or unstable clusters. Transfusion-related effects, comorbidities and mortality were described. Costs associated with RBC transfusions in the various strategy groups were analysed.

Results. Over the 118 transfusion records analysed, a restrictive strategy was adopted in 27 cases (22.9\%) and a modified liberal strategy was used in 68 cases (57.6\%). A mixed strategy was followed in 23 (19.5\%) cases. Although mortality was higher in the modified liberal group than in the restrictive group $(27.9 \% \mathrm{v} .11 .1 \%)$, the difference was not statistically different $(p=0.09)$. There were no differences in the duration of intermittent positive pressure ventilation, length of PICU stay or post-transfusion effects between the restrictive and modified liberal transfusion strategies. A saving of R155 280.15 could have been realised if a restrictive transfusion strategy had been used for haemodynamically stable patients assigned to the modified liberal group. A further R28 988.67 was spent on avoidable after-hours transfusions levies.

Conclusion. Adopting a restrictive daytime strategy for RBC transfusions at a PICU could introduce considerable cost savings without affecting outcomes.
\end{abstract}

S Afr J Child Health 2018;12(4):164-169. DOI:10.7196/SAJCH.2018.v12i4.1517

Anaemia, which refers to a blood haemoglobin level that is two standard deviations below the median age-dependent reference, is commonly seen in critically ill patients. It may be due to the underlying disease or treatment causing bone marrow suppression, overt or occult blood loss, inadequate erythropoietin response or nutritional deficiencies. ${ }^{[1]}$ Red blood cell (RBC) transfusions are aimed at increasing the haemoglobin concentration and hence increasing the cells' capacity for carrying and delivering oxygen to tissue. ${ }^{[2]}$ For patients not in an intensive care unit (ICU), the World Health Organization (WHO) defines a haemoglobin level $<4 \mathrm{~g} / \mathrm{dL}$ and $4-6 \mathrm{~g} / \mathrm{dL}$ as the cut-off for profound and severe anaemia, respectively.

Outcomes following severe anaemia are unsatisfactory, with an in-hospital mortality rate of $9-10 \%$ being reported, and a 6-month mortality rate of $12 \%{ }^{[3]}$ WHO guidelines encourage the rational use of blood transfusion to preserve this scarce resource and to reduce the risk of transfusion-transmitted infections ${ }^{[4]}$ and advocate paediatric blood transfusion to be reserved for children with a haemoglobin level $<4 \mathrm{~g} / \mathrm{dL}$ (or $<6 \mathrm{~g} / \mathrm{dL}$ if accompanied by complications). The haemoglobin threshold for RBC transfusion among septic patients is $<7 \mathrm{~g} / \mathrm{dL}^{[5,6]}$ The optimal haemoglobin threshold for blood transfusion in critically ill children remains uncertain. ${ }^{[7]}$

Up to $50 \%$ of all critically ill children admitted to a paediatric intensive care unit (PICU) will receive one or more RBC transfusions during their stay, increasing to $75 \%$ for children whose stay exceeds 7 days. ${ }^{[7-9]}$ There are limited published data on the decision tree guiding the paediatric intensivist to prescribe an RBC transfusion. ${ }^{[10]}$ In 2007, the Transfusion Strategies for Patients in Paediatric Intensive Care Units (TRIPICU) group suggested a haemoglobin threshold of $<7 \mathrm{~g} / \mathrm{dL}$ rather than $<9.5 \mathrm{~g} / \mathrm{dL}$ for prestored leukocyte-reduced RBC transfusion in stable critically ill children, as this would decrease mortality without increasing adverse outcomes and would reduce the requirement for RBC transfusions. ${ }^{[2]}$ This recommendation was supported by the guidelines of the American Association of Blood Banks. However, practising physicians suggested a haemoglobin threshold of $7-8 \mathrm{~g} / \mathrm{dL}$ as a trigger for transfusion, as there is no difference in mortality and length of hospital stay in adult patients when these levels are used. ${ }^{[11]}$ This recommendation was unusual, given the increased vulnerability of adult patients to adverse effects from the use of leukocyte-replete RBC transfusion, which is known to generate cytokines and activate an inflammatory response. ${ }^{[7]}$ Other adverse effects, including transfusion-associated lung injury, infections and transfusion reactions have been described among ICU patients who received RBC transfusions. ${ }^{[1,8,12,13]}$

Against this background, and considering the high cost of transfusions and the limited and erratic supply of blood products in Africa, ${ }^{[14]}$ we undertook a retrospective chart review to describe the outcomes and costs associated with different transfusion strategies used to treat critically ill anaemic children in a PICU.

\section{Methods}

Site

The PICU at the Inkosi Albert Luthuli Central Hospital in Durban, South Africa (SA), is a multidisciplinary public-sector tertiarylevel unit that serves a population of approximately 3 million children under the age of 12 years. The unit has 14 beds and admits approximately 500 - 600 children annually. Approximately $80 \%$ of admissions are due to emergencies, mostly (75\%) as a result of medical conditions. 


\section{Study population}

Records of RBC concentrate transfusions at the PICU during 2015 (1 January to 31 December) were obtained from the South African National Blood Service. To decide which cases to include in the study, electronic clinical records were reviewed according to predefined criteria based on the guidelines formulated by the TRIPICU study group. ${ }^{[7]}$ Patients were excluded from the study if:

- post conception age was $<40$ weeks

- the patient weighed $<3 \mathrm{~kg}$

- the patient was younger than 3 days or older than 12 years

- a decision to withhold or withdraw critical care was noted

- a blood exchange transfusion had been performed

- the patient was discharged $<24$ hours post transfusion

- acute blood loss was noted.

Cases were grouped according to whether the transfusion strategy was defined as restrictive, 'modified liberal' or mixed. Patients who received an $\mathrm{RBC}$ concentrate transfusion at a haemoglobin level $\leq 7.0 \mathrm{~g} / \mathrm{dL}$ were assigned to the restrictive group, whereas those who had received a transfusion at a haemoglobin level $>7 \mathrm{~g} / \mathrm{dL}$ were assigned to the 'modified liberal' group. The mixed group was made up of patients who had received multiple RBC concentrate transfusions, adopting a restrictive strategy on one occasion and a modified liberal strategy in another.

The classification 'modified liberal' was used to differentiate this strategy from the liberal strategy used in the TRIPICU study, for which a haemoglobin level $\geq 9.5 \mathrm{~g} / \mathrm{dL}$ was used as cut-off. ${ }^{[7]}$ In our study, the 'modified liberal' group was further subdivided based on haemodynamic stability at the point of transfusion. Haemodynamic instability was defined as any occurrence of hypotension or an increase in the use of inotropic support 24 hours prior to transfusion, whereas haemodynamically stable patients lacked these features. These definitions were modified from the TRIPICU study ${ }^{[7]}$ because of the retrospective nature of this review.

Demographic data, including age, gender, HIV status and primary and secondary diagnoses, were extracted from the electronic records of all the included cases. The severity of a patient's illness was defined according to the Paediatric Index of Mortality (PIM) 3 score at admission.

To evaluate adverse effects of RBC transfusions, vital signs and markers for sepsis and organ dysfunction as defined by the guidelines for surviving sepsis, were evaluated 24 hours before and 3 days after the transfusion. ${ }^{[2]}$ The number of days on intermittent positive-pressure ventilation (IPPV), length of PICU stay and mortality were considered in assessing the outcome associated with the different transfusion strategies. Both the cost of the RBC concentrate, according to transfusion strategy, and the levies associated with the transfusion were taken into account to evaluate the cost of an RBC transfusion. Factors considered to affect levies included the number of afterhours transfusions, the number of emergency and standard cross-matches performed, and the need for typing and screening. Afterhours transfusion levies are charged for any transfusion-related activity performed between 18:00 and 08:00 on weekdays and over weekends (between 18:00 on a Friday and 08:00 on a Saturday and between 13:00 on a Saturday and 08:00 on a Monday).

\section{Statistical analysis}

The four study groups were compared with regard to proportions and frequencies. Proportions were compared using chi-squared tests. Statistical significance was set at $p<0.05$.

\section{Ethical approval}

Approval for the study was obtained from the biomedical research ethics committee of the University of KwaZulu-Natal (ref. no. BE495/16) and the South African National Blood Service. As this was a retrospective study, informed consent was not obtained from patients.

\section{Results}

Of the 556 patients admitted to the unit in 2015, $203(36.5 \%)$ received a blood transfusion. The inclusion criteria were met in 118 of these cases (Fig. 1) and a total of 183 transfusions were performed. Of the included cases, 27 were classified as having had a restrictive transfusion strategy and 68 were assigned to the 'modified liberal' group. A mixed strategy was adopted in 23 of the included cases. In the 'modified liberal' group, 47 cases were haemodynamically stable and 21 were haemodynamically unstable. As shown in Fig. 1, cases were excluded mainly because patients weighed $<3 \mathrm{~kg}(n=46)$ or had suffered acute blood loss $(n=26)$.

\section{Baseline characteristics}

There were no significant differences in baseline characteristics (demographics, PIM score, number of transfusions and diagnoses) between the restrictive and 'modified liberal' (haemodynamically stable and unstable) groups (Table 1). Some patients in the 'modified liberal' group had more than one $\mathrm{RBC}$ transfusion and their haemodynamic status varied during the different $\mathrm{RBC}$ concentrate transfusions. The prevalence of HIV infection and the number of RBC transfusions were significantly higher among patients with a mixed transfusion strategy than among those in the other groups.

\section{Immediate effects post transfusion}

Physiological effects post transfusion are shown in Table 2. For these analyses, transfusions previously categorised as mixed were reclassified as either restrictive $(n=64)$ or modified liberal $(n=119)$. There were no significant differences in physiological parameters between the restrictive and modified liberal strategies post transfusion.

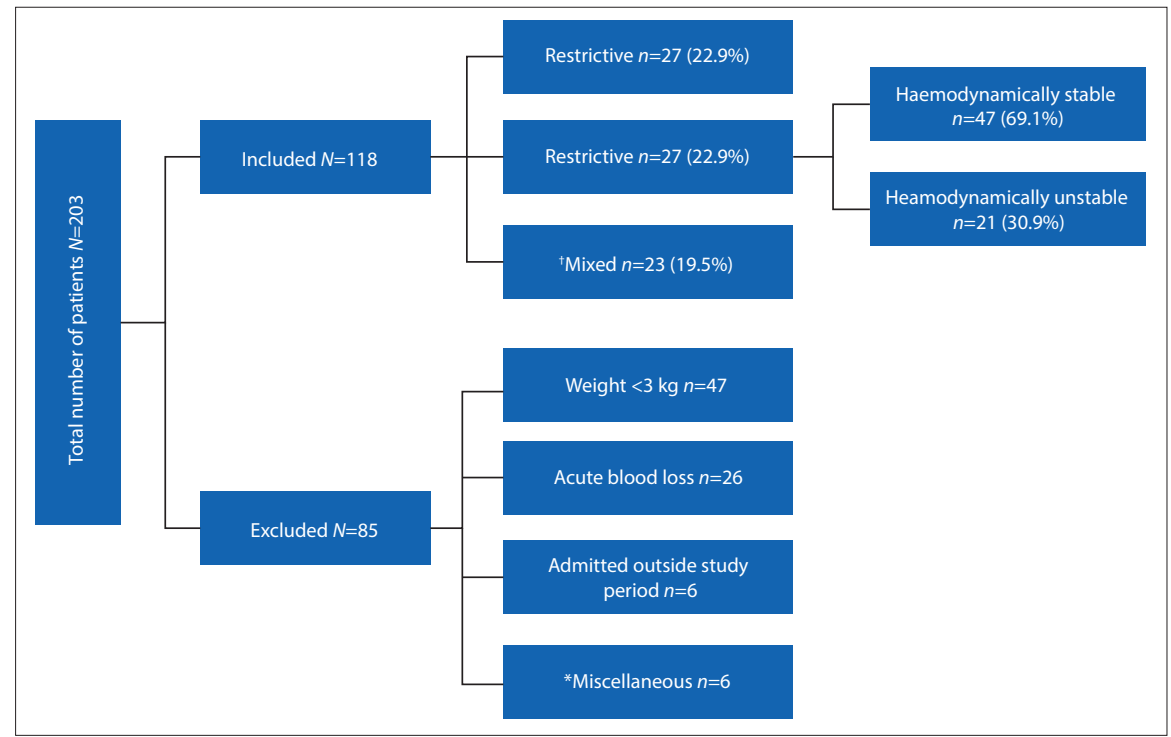

Fig. 1. Profile of the study population.

${ }^{*}$ Miscellaneous includes patients who were younger than 3 days or older than 12 years, discharged $<24$ hours post transfusion, or had a post conception age $<40$ weeks. Two patients were associated with each of these exclusion criteria.

${ }^{\dagger}$ The mixed cluster included patients who received transfusions based on both a modified liberal and restrictive strategy. 
Table 1. Baseline characteristics of study population categorised according to transfusion strategy $(N=118)$

\begin{tabular}{|c|c|c|c|c|c|c|}
\hline \multirow[b]{2}{*}{ Characteristics } & \multirow[b]{2}{*}{$\begin{array}{l}\text { Restrictive } \\
\text { strategy ( } n=27), \\
n(\%)\end{array}$} & \multicolumn{3}{|c|}{ Modified liberal strategy $(n=68), n(\%)$} & \multirow[b]{2}{*}{$\begin{array}{l}\text { Mixed strategy } \\
(n=23)\end{array}$} & \multirow[b]{2}{*}{$p$-value } \\
\hline & & $\begin{array}{l}\text { Haemodynamically } \\
\text { stable }(n=47), n(\%)\end{array}$ & $\begin{array}{l}\text { Haemodynamically } \\
\text { unstable }(n=21) \\
\text { n }(\%)\end{array}$ & Total $(n=68)$ & & \\
\hline Age (months), mean (range) & $13.9(1-120)$ & $11.6(0.3-120)$ & $18.8(0.16-144)$ & $11.4(0.16-144)$ & $8.8(1-108)$ & Ns \\
\hline Male & $17(63)$ & $25(53.2)$ & $11(52.4)$ & $36(52.9)$ & $12(52.2)$ & Ns \\
\hline HIV infected & $7(25.9)$ & $8(17)$ & $4(19)$ & $12(17.7)^{*}$ & $11(47.8)^{*}$ & 0.02 \\
\hline $\begin{array}{l}\text { No. of days prior to } \\
\text { transfusion, mean (range) }\end{array}$ & $5.3(0-35)$ & $3(0-29)$ & $3(1-16)$ & $5(0-29)$ & $5.9(1-18)$ & Ns \\
\hline $\begin{array}{l}\text { No. of transfusions, mean } \\
\text { (range) }\end{array}$ & $1.1(1-2)$ & $1(1-3)$ & $1(1-5)$ & $1.4(1-5)^{*}$ & $2.9(2-6)^{*}$ & 0.001 \\
\hline PIM score, mean (range) & $13.6(0.4-96.9)$ & $9.9(0.5-68.8)$ & $13.7(0.0-78.2)$ & $11.1(0.0-78.20)$ & $17.9(0.4-42.1)$ & Ns \\
\hline \multicolumn{7}{|l|}{ Primary diagnoses } \\
\hline Respiratory diseases & $9(33.3)$ & $14(29.8)$ & $5(23.8)$ & $19(27.9)$ & $6(26.1)$ & Ns \\
\hline HIV/AIDS & $6(22.2)$ & $8(17)$ & $4(19)$ & $12(17.7)^{*}$ & $11(47.8)^{*}$ & 0.02 \\
\hline Cardiac diseases & $1(3.7)$ & $12(25.5)$ & $5(23.8)$ & $17(25)$ & $0(0)$ & \\
\hline Sepsis & $1(3.7)$ & $4(8.5)$ & $2(9.5)$ & $6(8.8)$ & $2(8.7)$ & Ns \\
\hline Other & $10(37)$ & $9(19.1)$ & $5(23.8)$ & $14(20.6)$ & $4(17.4)$ & Ns \\
\hline \multicolumn{7}{|l|}{ Secondary diagnoses } \\
\hline Respiratory diseases & $15(55.6)$ & $19(40.4)$ & $7(33.3)$ & $26(38.2)$ & $12(52.2)$ & Ns \\
\hline Sepsis & $4(14.8)$ & $10(21.3)$ & $4(19)$ & $14(20.6)$ & $0(0)$ & Ns \\
\hline CNS & $1(3.7)$ & $6(14.6)$ & $0(0)$ & $6(8.8)$ & $2(8.7)$ & Ns \\
\hline Cardiac & $0(0)$ & $1(2.1)$ & $1(5)$ & $2(2.9)$ & $2(8.7)$ & Ns \\
\hline Other & $6(22.2)$ & $8(17)$ & $7(33.3)$ & $15(22.1)$ & $6(26.1)$ & Ns \\
\hline None & $1(3.7)$ & $3(6.4)$ & $2(9.5)$ & $5(7.4)$ & $1(4.4)$ & Ns \\
\hline
\end{tabular}

Table 2. Physiological effects associated with different transfusions ( $N=183)$

\begin{tabular}{|c|c|c|c|c|c|}
\hline Parameters & $\begin{array}{l}\text { Restrictive }^{\mathrm{a}}(n=64 \\
35 \%)\end{array}$ & $\begin{array}{l}\text { ML: Total }{ }^{b}(n=119 \\
65 \%)\end{array}$ & $\begin{array}{l}\text { ML: } \\
\text { Haemodynamically } \\
\text { stable }^{\mathrm{C}}(n=85 ; 71.4 \%)\end{array}$ & $\begin{array}{l}\text { ML: } \\
\text { Haemodynamically } \\
\text { unstable }^{\text {d }}(n=34 ; \\
28.6 \%)\end{array}$ & $\begin{array}{l}p \text {-value (a } \\
\text { v. b) }\end{array}$ \\
\hline $\begin{array}{l}\text { Pretransfusion } \\
\text { haemoglobin }(\mathrm{g} / \mathrm{dL}) \text {, } \\
\text { mean (range) }\end{array}$ & $6.4(4-7)$ & $8.3(7.1-12)$ & $8.3(7.1-12)$ & $8.5 .(1-10.5)$ & \\
\hline \multicolumn{6}{|c|}{ Relative difference in parameters post transfusion, \% } \\
\hline $\begin{array}{l}\text { Haemoglobin }(\mathrm{g} / \mathrm{dL}) \text {, } \\
\text { mean (range) }\end{array}$ & $3.8(2.04)$ & $2.3(2.73)$ & $2.6(2.6)$ & $1.6(3.0)$ & 0.0001 \\
\hline $\mathrm{P} / \mathrm{F} \mathrm{O}_{2}$ ratio $<300$ & 0 & 6.20 & -3.40 & -13.70 & 0.4 \\
\hline Heart rate & -1.60 & -1.68 & -2.30 & 0.00 & 0.9 \\
\hline Positive blood culture & 25 & -21.43 & -22.20 & -20.00 & 0.2 \\
\hline Temperature instability & -3.39 & -4.51 & -4.88 & -3.50 & 0.8 \\
\hline Procalcitonin & $-2.33^{*}$ & 5.06 & 1.79 & $13.00^{*}$ & 0.3 \\
\hline White blood cell & 0 & 12.28 & 12.20 & 12.50 & 0.1 \\
\hline Hypotension & $-4.76^{\dagger}$ & -6.80 & $9.40 \dagger$ & $-48.50^{\dagger}$ & 0.8 \\
\hline Change in inotrope & $-3.40 \S$ & -11.21 & 1.20 & $-41.20 \S$ & 0.1 \\
\hline Creatinine & $-4.76^{\ddagger}$ & 3.81 & $20.00^{\ddagger}$ & $17.30^{\ddagger}$ & 0.9 \\
\hline Urine output & -3.40 & -1.20 & 0.00 & 0.00 & 0.6 \\
\hline Platelets & 0 & 5.20 & 3.70 & 9.40 & 0.3 \\
\hline International ratio & -25 & -20 & 0 & -50 & 0.9 \\
\hline Bilirubin & 13.63 & - & - & - & - \\
\hline Lactate & -9.10 & 3.80 & 5.50 & 4 & 0.14 \\
\hline
\end{tabular}




\section{Clinical outcomes associated with different transfusion strategies}

As shown in Table 3, the modified liberal transfusion strategy was associated with a higher mortality rate $(27.9 \%)$ than the restrictive (11.1\%) strategy. Similarly, a higher mortality rate was seen in the haemodynamically unstable $(42.9 \%)$ group than in the stable group $(21.3 \%)$. There was no statistically significant difference in the mortality rate between patients in the restrictive and haemodynamically stable groups $(p=0.3)$, but a statistical difference in mortality was found when the restrictive and haemodynamically unstable cases were compared $(p=0.03)$. There was no statistical difference in the duration of IPPV or length of ICU stay between the restrictive strategy and any of the subgroups of the modified liberal strategy. Patients in the mixed transfusion group had the worst outcomes across all the clinical parameters.

\section{Costs related to transfusion}

The cost of a paediatric RBC concentrate pack was R1 485.65 in 2015. The 74 transfusion units used for the restrictive group amounted to a total cost of R119 065.94, while the 132 transfusion units used in the 'modified liberal' group amounted to R225 428.61 (Table 4A). If a restrictive strategy had been used for the haemodynamically stable patients in the modified liberal group, a cost saving of R155 280.15 would have been realised. This decision would not have increased the risk of mortality or prolonged ICU stay.
The levies associated with a transfusion, and the consequent effect of the transfusion strategy and decision on the cost of a transfusion, are shown in Table 4B. Of the total number of transfusions, 74 (40.4\%) were unnecessarily performed after hours, which resulted in an additional cost of R26 746.50 for after-hours transfusion levies and another R2 242.17 for unnecessary after-hours typing and screening.

\section{Discussion}

Our findings support the implementation of a restrictive strategy for $\mathrm{RBC}$ transfusions, as patients in this group had the lowest mortality rate and did not show an increased need for intensive care. Although mortality rates cannot strictly be compared among the three strategies in a retrospective chart review, the similarities in demographic data, primary and secondary diagnoses and severity of disease seen among these groups allow for cautious comparisons. Differences in haemodynamic stability may have led to haemodynamically stable patients in the modified liberal group having better outcomes, similar to those in the restrictive group, whereas outcomes for haemodynamically unstable patients in this group tended towards those associated with the mixed group. Studies among larger randomised paediatric and neonatal critical care populations have yielded similar findings, with restrictive transfusion strategies reducing the need for transfusion without increasing morbidity or mortality. ${ }^{[7,15]}$ Over 30 randomised trials across more than 12000 adult patients have consistently shown that a restrictive transfusion

Table 3. Clinical outcomes of patients $(N=118)$ in the different transfusion strategy groups

\begin{tabular}{|c|c|c|c|c|c|c|}
\hline \multirow[b]{2}{*}{ Outcomes } & \multirow{2}{*}{$\begin{array}{l}\text { Restrictive }^{\mathrm{a}} \\
(n=27)\end{array}$} & \multicolumn{3}{|c|}{ Modified liberal $^{b}$} & \multirow[b]{2}{*}{$\operatorname{Mixed}^{\mathrm{C}}(n=23)$} & \multirow[b]{2}{*}{$p$-values } \\
\hline & & Stable $(n=47)$ & Unstable $(n=21)$ & Total $(n=68)$ & & \\
\hline $\begin{array}{l}\text { Duration of } \\
\text { mechanical } \\
\text { ventilation (days), } \\
\text { mean (range) }\end{array}$ & $8.6(0-35)^{\star}$ & $10.9(0-50)$ & $10.8(2-42)$ & $10.9(0-50)^{\star}$ & $20.8(6-48)$ & $\begin{array}{l}\text { c v. a: } p<0.001 \\
\text { c v. b: } p<0.001 \\
\text { c v. d: } p<0.001 \\
\text { c v. e: } p<0.001\end{array}$ \\
\hline $\begin{array}{l}\text { PICU stay (days), } \\
\text { mean (range) }\end{array}$ & $10.8(2-38)^{\dagger}$ & $12.9(4-63)$ & $13.9(2-50)$ & $13.2(2-63)$ & $23.9(12-47)^{\dagger}$ & $\begin{array}{l}\text { c v. a: } p<0.001 \\
\text { c v. b: } p<0.001 \\
\text { c v. d: } p<0.001 \\
\text { c v. e: } p<0.001\end{array}$ \\
\hline $\begin{array}{l}\text { Mortality in PICU } \\
(N=118), n(\%)\end{array}$ & $3(11.1)$ & $10(21.3)$ & $9(42.9)$ & $19(27.9)$ & $13(56.5)$ & $\begin{array}{l}\text { a v. e: } p<0.02 \\
\text { d v. c: } p=0.004 \\
\text { b v. c: } p=0.002\end{array}$ \\
\hline $\begin{array}{l}\text { *a v. b: } p>0.05 \\
\dagger_{\text {a v }} \text { d: } p>0.05 \\
\text { PICU }=\text { paediatric inter }\end{array}$ & sive care unit. & & & & & \\
\hline
\end{tabular}

Table 4A. Costing variables and subsequent costs associated with different transfusions $(N=183)$

\begin{tabular}{|c|c|c|c|c|}
\hline \multirow[b]{2}{*}{ Costing variables } & \multirow[b]{2}{*}{ Restrictive $(n=64 ; 35 \%)$} & \multicolumn{3}{|c|}{ Modified liberal } \\
\hline & & $\begin{array}{l}\text { Haemodynamically stable } \\
(n=85 ; 46.4 \%)\end{array}$ & $\begin{array}{l}\text { Haemodynamically } \\
\text { unstable }(n=34 ; 18.6 \%)\end{array}$ & Total $(n=119 ; 65 \%)$ \\
\hline \multicolumn{5}{|c|}{ Timing of decision to transfuse, $n(\%)$} \\
\hline Day & $53(82.8)$ & $71(84)$ & $27(79)$ & $98(82.4)$ \\
\hline Night* & $6(9.4)$ & $6(7.1)$ & $3(8.8)$ & $9(7.6)$ \\
\hline Unknown & $5(7.8)$ & $8(9)$ & $4(12)$ & $12(10.1)$ \\
\hline \multicolumn{5}{|l|}{ Transfusion time } \\
\hline Day & $27(42.2)$ & $31(36.5)$ & $19(55.9)$ & $50(42)$ \\
\hline Night & $37(57.8)$ & $54(63.5)$ & $15(44.1)$ & $69(58)$ \\
\hline Units transfused & 74 & 93 & 39 & 132 \\
\hline Total transfusion $\operatorname{cost}^{* *}$ & R119 065.94 & R155 280.15 & R70 148.46 & R225 428.61 \\
\hline
\end{tabular}


Table 4B. Levies associated with transfusion decisions $(N=183)$

\begin{tabular}{|c|c|c|c|c|}
\hline \multirow[b]{2}{*}{ Levy description } & \multirow[b]{2}{*}{ Restrictive $(n=64 ; 35 \%)$} & \multicolumn{3}{|c|}{ Modified liberal } \\
\hline & & $\begin{array}{l}\text { Haemodynamically stable } \\
(n=85 ; 46.4 \%)\end{array}$ & $\begin{array}{l}\text { Haemodynamically } \\
\text { unstable }(n=34 ; 18.6 \%)\end{array}$ & Total $(n=119 ; 65 \%)$ \\
\hline \multicolumn{5}{|l|}{ Unavoidable } \\
\hline Routine cross-match & R2 861.16 & R4 291.74 & R1 430.58 & R5 722.32 \\
\hline Emergency cross-match & R1 213.02 & R1 617.36 & R1 347.80 & R2 965.16 \\
\hline \multicolumn{5}{|l|}{ Avoidable } \\
\hline $\begin{array}{l}\text { Unnecessary after-hours } \\
\text { transfusion, } n(\%)\end{array}$ & $26(40.6)$ & $40(47)$ & $8(23.5)$ & $48(40.3)$ \\
\hline After-hours levy* & R9 397.40 & R14 457.60 & R2 891.50 & R17 349.10 \\
\hline Type and screen & R640.62 & R960.93 & R640.62 & R1 601.55 \\
\hline
\end{tabular}

strategy (with haemoglobin levels at $\leq 7 \mathrm{~g} / \mathrm{dL}$ ) does not adversely affect clinical outcome. ${ }^{[16]}$ Similar to the findings of our study, the TRIPICU study - the only robust trial in children - has not shown any differences in mortality or multiple organ dysfunction syndromes between patients for whom a restrictive strategy was adopted and haemodynamically stable patients when a more liberal strategy was used. ${ }^{[17]}$ The TRIPICU study further recommends a restrictive transfusion strategy for stable PICU patients, but not for premature infants, older children, patients with coronary artery disease, or children with severe hypoxaemia, haemodynamic instability, active blood loss or cyanotic heart disease. ${ }^{[7]}$ In children with more severe illness or for those in specific subpopulations, such as recovering after cardiac surgery, transfusions were initiated at higher haemoglobin levels. ${ }^{[10]}$

Our study further also highlighted the considerable cost associated with RBC transfusions. In a retrospective descriptive study from Mexico, Cázares-Benito et al.$^{[18]}$ concluded that the use of blood transfusion in cases not indicated by the guidelines of the American Association of Blood Banks impacted notably on total health cost. Blood products for transfusion are often in short supply and constitute a large part of a hospital's medicine budget. High usage puts a considerable financial burden on resourcelimited institutions. Adopting a restrictive transfusion strategy may reduce the demand for blood transfusion, and so help to manage associated costs. In a study among patients with septic shock, randomised to receive $\mathrm{RBC}$ transfusions at either a low or a high haemoglobin threshold, a median of 1 unit of blood was saved in the low-threshold group for a median of every 4 units utilised. ${ }^{[5]}$ It is not clear exactly how many RBC transfusions could have been saved in our study had a restrictive strategy been implemented, but a study from elsewhere in SA showed that implementing a restrictive transfusion strategy exclusively resulted in half the number of RBC transfusions being performed, with considerable cost savings reported. ${ }^{[19]}$ Implementing a restrictive transfusion strategy may decrease the overuse of RBC transfusions, thereby reducing the associated risks and costs. ${ }^{[20]}$

Another-cost saving strategy could be to enforce a daytime transfusion policy, which would eliminate paying levies for afterhours transfusions. It is possible that institutions fail to implement a daytime transfusion policy because of a lack of awareness of the financial implications of an after-hours transfusion practice and the associated delivery and retrieval processes among staff. Unavoidable levies such as for emergency cross-matches should be restricted, as blood can often be obtained within 45 minutes with routine services. Blood typing and screening should be severely restricted as it does little to save time if blood is required. The use of an audit form to monitor all decisions related to the use of blood products is recommended, as this has been shown to reduce the need for RBC transfusions and associated costs effectively. ${ }^{[21]}$

Another important finding of this study was the lack of any serious physiological variance between the pre- and posttransfusion parameters for the restrictive or the modified liberal transfusion groups. This suggests that the haemoglobin cut-off level, the haemodynamic stability, the primary and secondary diagnoses and the severity of illness at transfusion were not affected by the transfusion process. All transfusions were leucocyte depleted, which may account for the lack of acute transfusionrelated lung injury, multi-organ dysfunction, cardiac overload and nosocomial infections. Three studies from Kenya have shown that severe anaemia can be dangerous in the hospitalised paediatric population, as mortality rates were significantly higher in patients with haemoglobin levels $<5 \mathrm{~g} / \mathrm{dL}$. The risk of mortality decreased with receipt of RBC transfusions. ${ }^{[6,22,23]}$

\section{Study limitations}

There were several limitations in this study. This was a singlecentre, retrospective study, with some missing data and a smaller sample size than what was used in the TRIPICU study, which limits its external validity Defining the severity of subjects' illness was challenging and our definition of haemodynamic stability did not match that of the TRIPICU study, nor was a distinction made between cyanotic or acyanotic cardiac lesions. In addition, the transfusion service was used as a primary source for patient recruitment. However, the study yielded useful results overall, as it was performed in a large tertiary centre and analysed transfusion parameters over a 1-year period.

\section{Conclusion}

It could be prudent to adopt a restrictive RBC transfusion strategy in a PICU. Such a change is unlikely to increase mortality risk, the need for mechanical ventilation or ICU stay, and could reduce a unit's operating cost with regard to transfusions. Our unit has since adopted this strategy. A prospective randomised study to compare the effects of transfusing at different predefined haemoglobin cut-off levels in critically ill children is still required.

Acknowledgements. We would like to thank the chief executive office at Inkosi Albert Luthuli Central Hospital for permission to conduct the study, the staff of ICU4 for caring for the enrolled patients, and the South African National Blood Service for allowing access to their database. We thank Ms Catherine Connolly, biostatistician in the Discipline of Public Health Medicine, University of KwaZulu-Natal, for her assistance with statistical analysis.

Author contributions. PBSR designed the study, collected data and wrote 
the manuscript. PMJ acted as supervisor and assisted in refining the design, data analysis and interpretation, and revising earlier drafts of the manuscript.

\section{Funding. None.}

Conflicts of interest. None.

1. Bateman ST, Lacroix J, Boven K, et al. Anemia, blood loss, and blood transfusions in North American children in the intensive care unit. Am J Respir Crit Care Med 2008;178(1):26-33. https://doi.org/10.1164/rccm.200711-1637oc

2. Demaret P, Tucci M, Ducruet T, Trottier H, Lacroix J. Red blood cell transfusion in critically ill children. Transfusion 2014;54:365-375. https://doi.org/10.1111/ trf.12261

3. Brabin BJ, Premji Z, Verhoeff F. An analysis of anemia and child mortality. J Nutr 2001;131(2):636S-648S. https://doi.org/10.1093/jn/131.2.636s

4. World Health Organization. Pocket book of Hospital Care for Children: Guidelines for the Management of Common Childhood Illnesses. 2nd ed. Geneva: WHO, 2013.

5. Holst LB, Haase N, Wetterslev J, et al. Lower versus higher hemoglobin threshold for transfusion in septic shock. N Engl J Med 2014;371(15):13811391. http://doi.org/10.1056/nejmoa1406617

6. Lackritz EM, Hightower AW, Zucker JR, et al. Longitudinal evaluation of severely anemic children in Kenya: The effect of transfusion on mortality and hematologic recovery. AIDS 1997;11(12):1487-1494. https://doi. org/10.1097/00002030-199712000-00013

7. Lacroix J, Hébert PC, Hutchison JS, et al. Transfusion strategies for patients in pediatric intensive care units. N Engl J Med 2007;356(16):1609-1619. http://doi. org/10.1056/nejmoa066240

8. Kneyber MCJ, Hersi MI, Twisk JWR, Markhorst DG, Plötz FB. Red blood cell transfusion in critically ill children is independently associated with increased mortality. Intensive Care Med 2007;33(8):1414-1422. https://doi.org/10.1007/ s00134-007-0741-9

9. Istaphanous GK, Wheeler DS, Lisco SJ, Shander A. Red blood cell transfusion in critically ill children: A narrative review. Pediatr Crit Care Med 2011;12(2):174183. https://doi.org/10.1097/pcc.0b013e3181e30d09

10. Lacroix J, Demaret P, Tucci M. Red blood cell transfusion: Decision making in pediatric intensive care units. Semin Perinatol 2012;36(4):225-231. https://doi. org/10.1053/j.semperi.2012.04.002

11. Carson JL. Red blood cell transfusion: A clinical practice guideline from the AABB. Ann Intern Med 2012;157(1):49-58. https://doi.org/10.7326/0003-4819156-12-201206190-00429
12. Corwin HL, Gettinger A, Pearl RG, et al. The CRIT study: Anemia and blood transfusion in the critically ill - current clinical practice in the United States. Crit Care Med 2004;32(1):39-52. https://doi.org/10.1097/01. ccm.0000104112.34142.79

13. Akyildiz B, Ulgen Tekerek N, Pamukcu O, et al. Comprehensive analysis of liberal and restrictive transfusion strategies in pediatric intensive care unit. J Trop Pediatr 2018;64(2):118-125. https://doi.org/10.1093/tropej/fmx037

14. Ala F, Allain J-P, Bates I, et al. External financial aid to blood transfusion services in sub-Saharan Africa: A need for reflection. PLoS Med 2012;9(9):e1001309. https://doi.org/10.1371/journal.pmed.1001309

15. Kirpalani H, Whyte RK, Andersen C, et al. The Premature Infants in Need of Transfusion (PINT) study: A randomized, controlled trial of a restrictive (low) versus liberal (high) transfusion threshold for extremely low birth weight infants. J Pediatr 2006;149(3):301-307. https://doi.org/10.1016/j. jpeds.2006.05.011

16. Carson JL, Carless PA, Hebert PC. Transfusion thresholds and other strategies for guiding allogeneic red blood cell transfusion. Cochrane Database Syst Rev 2012;4:CD002042. http://doi.org/10.1002/14651858.cd002042.pub3

17. Goel R, Cushing MM, Tobian AAR. Pediatric patient blood management programs: Not just transfusing little adults. Transfus Med Rev 2016;30(4):235241. http://doi.org/10.1016/j.tmrv.2016.07.004

18. Cázares-Benito MA, Cázares-Tamez R, Pérez-Chávez F, et al. Impact on costs related to inadequate indication of blood transfusion. Medicina Universitaria 2016;18(72):148-152. http://doi.org/10.1016/j.rmu.2016.07.003

19. Harrison MC, Pillay S, Joolay Y, et al. Resource implications of adopting a restrictive neonatal blood transfusion policy. S Afr Med J 2013;103(12):916917. http://doi.org/10.7196/samj.6858

20. Klaus SA, Frank SM, Salazar JH, et al. Hemoglobin thresholds for transfusion in pediatric patients at a large academic health center. Transfusion 2015;55(12):2890-2897. http://doi.org/10.1111/trf.13296

21. Wise R. Saving blood, saving lives - an innovative rational blood utilization project. World Hosp Health Serv 2017;53(1):23-25.

22. Lackritz EM, Campbell CC, Ruebush TK, Hightower AW, Wakube W, Were JBO. Effect of blood transfusion on survival among children in a Kenyan hospital. Lancet 1992;340(8818):524-528. http://doi.org/10.1016/0140-6736(92)91719-o

23. English M, Ahmed M, Ngando C, Berkley J, Ross A. Blood transfusion for severe anaemia in children in a Kenyan hospital. Lancet 2002;359(9305):494495. http://doi.org/10.1016/s0140-6736(02)07666-3

Accepted 25 May 2018 